International Journal of Engineering \& Technology, 7 (3.27) (2018) 73-76
International Journal of Engineering \& Technology
SPC
Website: www.sciencepubco.com/index.php/IJET
Research paper

\title{
Smart Street Solutions Using Iot
}

\author{
E. Ganesh Kumar ${ }^{1 *}$, Kandhadai Anusha², V. Saipriya ${ }^{3}$, P. Dass ${ }^{4}$ \\ ${ }^{1}$ Final Year, Department of ECE, Saveetha School of Engineering, Chennai, Tamil Nadu, India. \\ ${ }^{2}$ Final Year, Department of ECE, Saveetha School of Engineering, Chennai, Tamil Nadu, India. \\ E-mail:kandhadaianusha06@gmail.com \\ ${ }^{3}$ Final Year, Department of ECE, Saveetha School of Engineering, Chennai, Tamil Nadu, India. \\ E-mail:saipriya.13101996@gmail.com \\ ${ }^{4}$ Assistant Professor(O.G), Department of ECE, Saveetha School of Engineering, Chennai, Tamil Nadu, India. \\ E-mail:dasseie@gmail.com \\ *Corresponding author E-mail:ganeshkumarinteliot@gmail.com
}

\begin{abstract}
Street light failure has become a major problem in cities nowadays. As the failure reports are sent very rare to government, these failures are checked only if a higher involvement action takes place. Monitoring of street lights and controlling is of utmost importance in developing country like India. Moreover, in today's world, power saving is very important and difficult. Though there are many power generation methods, it has become very difficult due to insufficient resources. Considering this as a problem, this project is developed to send accurate location of fuse blown street light to a contact number (if government number provided). When a Street light doesn't glow even after it is powered ON, the light detector circuit detects which is immediately sent to an Intel® Edison processor which processes the information. A GSM Module is attached to it, which sends the location of the blown fuse street light to the respective contact number.
\end{abstract}

Keywords: Street lights, light detector, GSM messaging, intel edison, power consumption.

\section{Introduction}

Most of the countries especially India is installing smart street lights in many cities. If the street lights are not maintained properly then the installation of these smart street lights will become a failure.

Moreover, street lights which were installed nowadays gets damaged soon, consumes more power and gives less brightness. During some rainy seasons, winter seasons these street lights provides a way for the passengers to walk. If it is not maintained properly this will create a problem for daily life. It totally upsets the routine life of public. If the street lights in urban cities are not maintained properly, there will be a huge chance of occurrence of accidents and people will feel inconvenient to walk in roads at nights. Many theft cases may occur, many accidents may occur and many people may fall into holes or drainages if there is no street light in nights.

As these problems occur in many cities, we have developed a prototype to minimize this problem. The developed prototype will continuously monitor the street lights at night. If there is a failure detected, it immediately sends the report to a mobile number. The detailed report of message is given in working section. Thus this project minimizes the failure of street light and hence there will be a reduction in accidents and thefts.

\section{Tools Used}

\section{Hardware Tools Used}

- $\quad$ Intel Edison Computing Module

- $\quad$ SIM 900 GSM Module

- $\quad$ LDR Sensor

- Relay Module

\section{Software Tools Used}

- $\quad$ Arduino IDE open source software.

- Putty

- Intel Edison Driver Software

- $\quad$ Google Maps 


\section{Block Diagram}

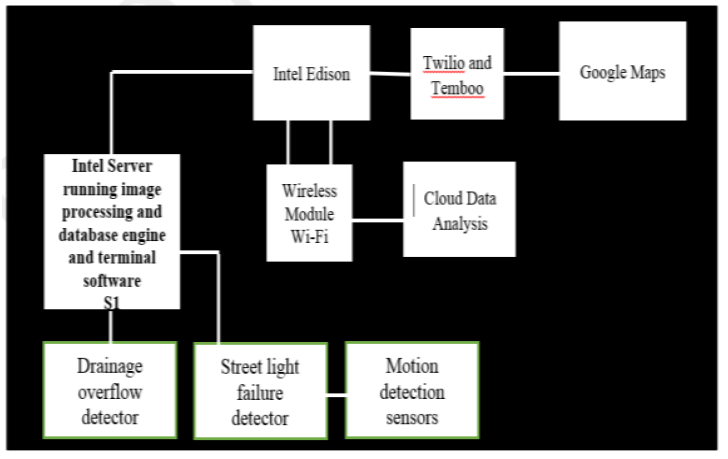

Figure 1.1: Block diagram

\section{Description}

\section{Intel Edison Computing Module}

The Intel ${ }^{\circledR}$ Edison development platform is designed to lower the barriers to entry for a range of inventors, entrepreneurs, and consumer product designers to rapidly prototype and produce "Internet of Things" (IoT) and wearable computing products[2]. Supports Arduino Sketch, Linux, Wi-Fi, and Bluetooth. Board I/O: Compatible with Arduino Uno (except 4 PWM instead of 6 PWM):

- 20 digital input/output pins, including 4 pins as PWM outputs.

- 6 analog inputs.

- 1 UART $(\mathrm{Rx} / \mathrm{Tx})$.

- 1 I2C.

- 1 ICSP 6-pin header (SPI).

- Micro USB device connector OR (via mechanical switch) dedicated standard size USB host Type-A connector.

- $\quad$ Micro USB device (connected to UART).

- $\quad$ SD card connector.

- $\quad$ DC power jack (7 to15VDC input)[2].

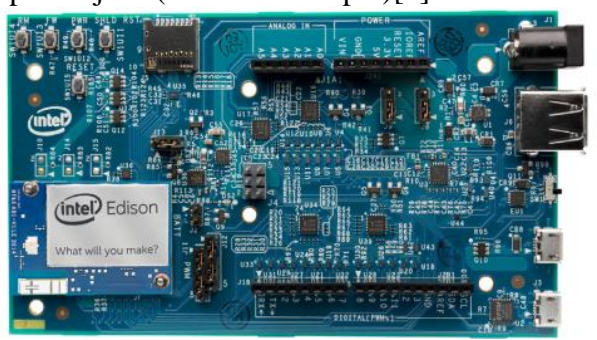

Figure 1.2: Intel edison computing module [3]

\section{Light Dependent Resistor}

An LDR is an electronic component that has a resistance which changes with the intensity of light that falls upon it. This makes them to use it in light sensing circuits. The most common type of Light Dependent Resistor has a resistance that falls with an increase in intensity of light falling upon the device. The symbol of LDR is shown in figure.

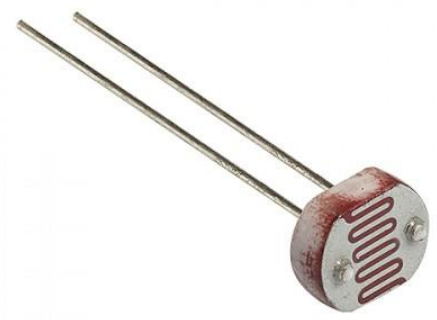

Figure 1.3: Light dependent resistor

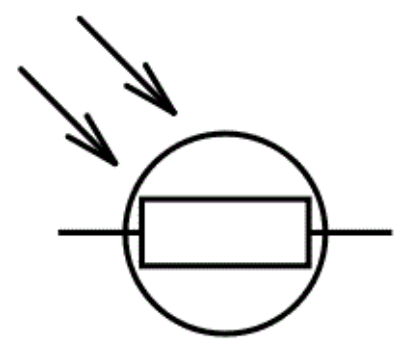

Figure 1.4: LDR symbol

A LDR may typically have the following resistances.

- $\quad$ Daylight $=5000 \Omega$

- $\quad$ Dark $=20000000 \Omega$

Therefore one can see that there is a huge variation among these resistances. If we plot this variation on a graph we will get something similar to the figure of graph shown above.

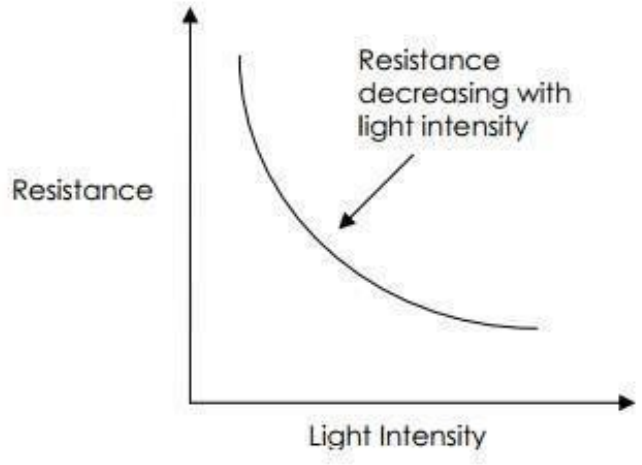

Figure 1.5: Variation graph

The most highly used application of an LDR is to automatically turn on the light at a certain light level. For example, this could be used in a street light or a garden light.

LDRs can be used to control the shutter speed on a camera. The LDR would be used to measure the light intensity which then adjusts the camera shutter speed to the appropriate level [6].

\section{LDR sensor}

This circuit shown in figure is a simple way of constructing a LDR sensor that turns on when it goes dark. In this LDR sensor circuit the LDR and the Resistors form a simple 'Voltage Divider Biasing' circuit, where the centre joining point of the Voltage Divider is connected to the Base terminal of a NPN Transistor. 


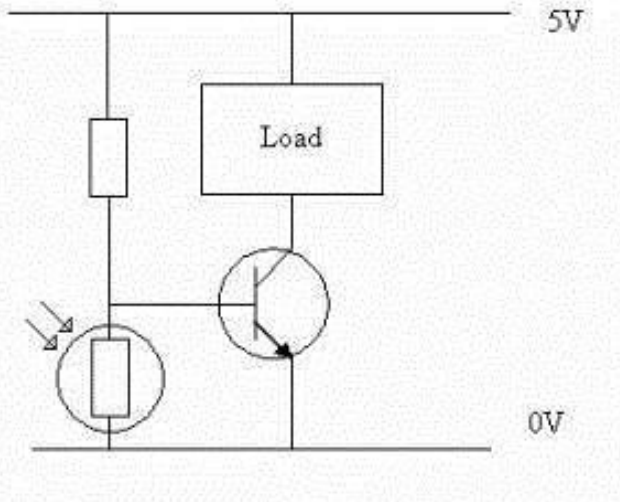

Figure 1.6: Simple LDR sensor circuit

When the intensity of light decreases, the resistance of LDR increases. As the resistance of LDR increases the other Resistors which are in relation to it, which has a fixed resistance, causes the voltage drop across the LDR to increase. When this voltage is large enough i.e. $0.7 \mathrm{~V}$ for a typical NPN Transistor, it will cause the NPN Transistor to turn on.

The values of the fixed resistor will depend upon the transistor used and the voltage supplied to it.

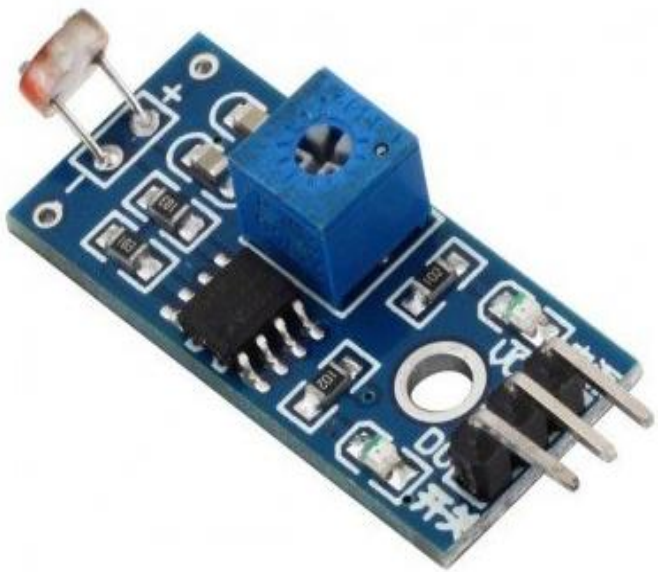

Figure 1.7: LDR sensor

\section{Relay Switch Circuit}

A Relay is an electromechanical device which uses an electromagnet to operate a pair of movable contacts from an open position to a closed position.

A relay takes relatively a small amount of power to operate the relay coil, but can be used in AC circuits, controlling motors, heaters, lamps which draws a lot more electrical power. In simple way, it is a switch with very low input voltage and turns on a high voltage appliance.

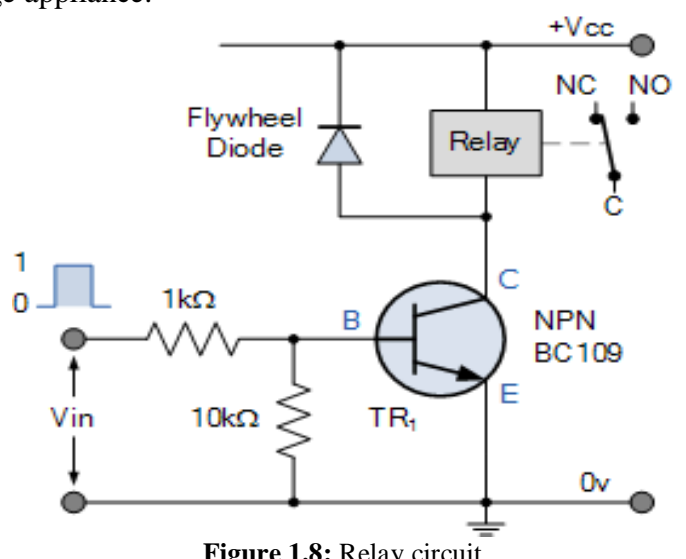

Figure 1.8: Relay circuit
The electromechanical relay is an output device which comes in a variety of shapes, designs, sizes and specifications and have a lot of uses in electronic circuits such as automatic switching ' $O N$ ' and 'OFF'.

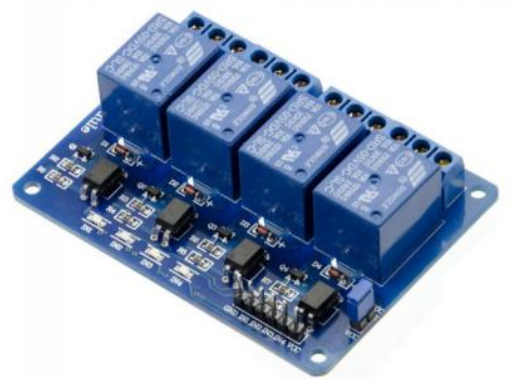

Figure 1.9: Relay module

\section{GSM Module}

GSM stands for global system for mobile communication (GSM) which is a mobile communication module. GSM is a digital cellular technology which is used to transmit mobile voice and data services that operates at the range of $850 \mathrm{MHz}, 900 \mathrm{MHz}$, $1800 \mathrm{MHz}$ and $1900 \mathrm{MHz}$ frequency bands.

GSM is a digital system that uses time division multiple access (TDMA) technique for communication purpose. The digital system has an ability to carry $64 \mathrm{kbps}$ to $120 \mathrm{Mbps}$ of data rates [4].

A GSM module is a device which can be used to make a processor communicate over a network. A GSM module requires a SIM card to be inserted in it in order to be operated and operates over a large network range. It can be connected through serial, USB or Bluetooth connection. [12]

GSM will allow "anywhere, anytime, and with anyone" communication. The GSM functional architecture employs intelligent networking principles, which provides its development to the first step towards a true personal communication system that is standardized enough to ensure compatibility and security.[13]

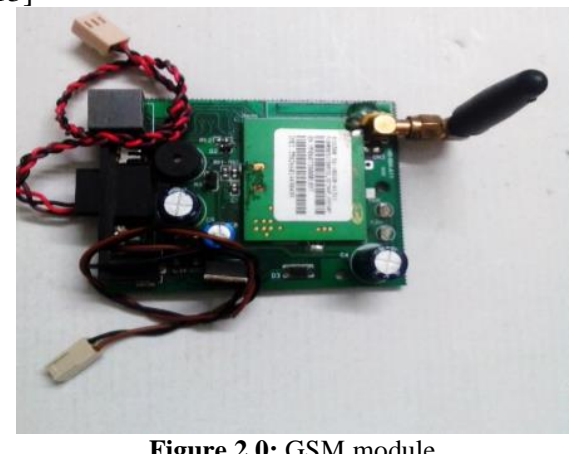

Figure 2.0: GSM module

Features of GSM Module:

- $\quad$ Short message service (SMS)

- $\quad$ Fixed dialing number (FDN)

- Real time clock with alarm management

- Compatibility with integrated services digital network (ISDN)

- It has Support for new services.

- Improved spectrum efficiency

- High-quality speech

- Uses encryption to make phone calls with more secure

\section{Working}

As shown in block diagram, it consists of light sensing circuit which uses light dependent resistor to sense the light. The LDR 
varies its resistivity according to the light that falls on it. The Edison has an input and output voltage of only $5 \mathrm{~V}$ and hence Relay module is used to detect or control a $230 \mathrm{~V}$ AC lamp. The $230 \mathrm{~V}$ lamp is connected to the COM terminal of relay and input for that relay is given via A and B terminals.

The output of light sensing circuit is given to the analog input pins (A0-A5) of Intel Edison; thus if there is failure in light, the light detector circuit detects and the value of the analog pin changes.

The Intel Edison is programmed in such a way that if there is change in analog input values, process the code embedded in the Edison Board. The location of each street light is fed in the Intel Edison. The GSM Module sends the location message to the respective number given in the Intel Edison code. The location fed in the Intel Edison can be viewed in any maps especially it is a Google Maps location with the latitude and longitude of the street light. Thus the entire setup works.

Example message is:

Failure in Street light 1.

Location:https://www.google.co.in/maps/place/13\%C2\%B001'11. $1 \% 22 \mathrm{E}$.

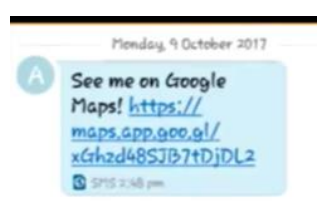

Figure 2.1: Message received

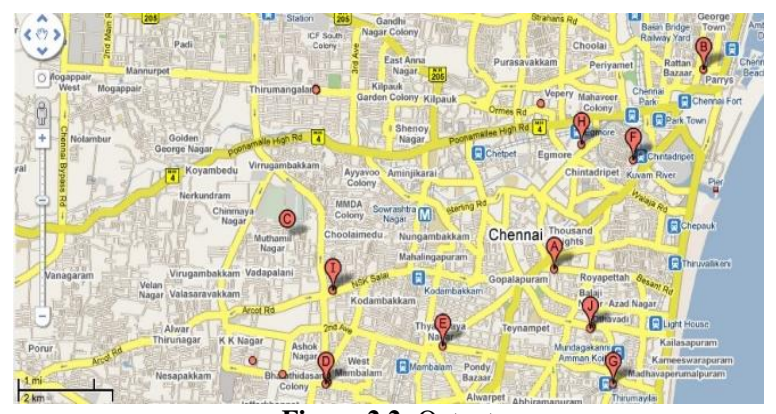

Figure 2.2: Output

\section{Conclusion and Future Scope}

The implementation of this project will provide a great security to people as there are many thefts occurring nowadays because of no street lights. Many people fall in manholes because of no light in nights. Power consumption is reduced. Immediate message sent when failure detected.

In the block diagram we have shown motion detection sensors, which will turn on street lights only when there is a movement of object. This makes street light to consume energy only when there is a motion detected. So power consumed is much recued.

The block diagram also shows a Wi-fi connectivity with the processor. This makes the processor to communicate with cloud services such as thing speak. The advantage of this is that, instead of using GSM, we can directly monitor in Thing speak from anywhere in the world and at any time. We are working on these modifications and advancements.

Not only these, there can be many more advancements which we can be done with this prototype in future.

\section{References}

[1] Lakshmiprasad K, "Smart Street Lights", International Journal of student Research in Technology and Management, (2014), pp.5963.

[2] The Hands-on Intel Edison Manual Lab, Google Books.

[3] https://communities.intel.com/thread/109754

[4] https://www.elprocus.com/gsm-architecture-features-working/

[5] https://en.wikipedia.org/wiki/Secure_Terminal_Equipment
[6] https://www.kitronik.co.uk/blog/how-an-ldr-light-dependentresistor-works/

[7] http://www.engineersgarage.com

[8] Ali F, Suri MA, Khan SU, Khan SU \& Rehman TU, "The Role of Current Technology in Street Light System", International Journal of Computer Engineering and Information Technology, Vol.8, No.8,(2016), pp.141-145.

[9] Villalobos Antúnez, JV (2017). Karl R. Popper, Heráclito y la invención del logos. Un contexto para la Filosofía de las Ciencias Sociales. Opción Vol. 33, Núm. 84. 5-11

[10] Archana G, Aishwarya N, Anitha J \& Vijay Kumar, "Intelligent Street Light System", International Journal of Recent Advances in Engineering \& Technology (IJRAET), Vol.3, No.4, (2015).

[11] Archana M \& Mahalahshmi R, "E-Street: LED Powered Intelligent Street Lighting System with Automatic Brightness Adjustment Based On Climatic Conditions and Vehicle Movements", International Journal of Advanced Research in Electrical, Electronics and Instrumentation Engineering, Vol.3, (2014).

[12] Rubananth R \& Kavitha T, "GSM Based RFID Approach to Automatic Street Lighting System", Journal of Theoretical and Applied Information Technology, Vol.38, No.2, (2012).

[13] M Pallarès Piquer and O Chiva Bartoll (2017). La teoría de la educación desde la filosofía de Xavier Zubiri. Opción, Año 33, No. 82 (2017): 91-113 